\title{
Influencia del estrés en la conducta maternal en hembras de ratón
}

\author{
María Isabel Orejuela Álvarez \\ al269510@uji.es \\ María Pilar García Pardo \\ mapardo@uji.es \\ Hugo Salais López \\ salais@uji.es \\ Manuela Barneo Muñoz \\ barneo@uji.es \\ Fernando Martínez García \\ femartin@uji.es
}

\section{Resumen}

El comportamiento maternal asegura la supervivencia de la descendencia hasta alcanzar la madurez sexual. Se trata de una conducta regulada por el cerebro socio-sexual y diferentes factores (como el estrés) pueden alterar los núcleos neuronales que rigen su funcionamiento. Así, el objetivo del presente trabajo será revisar la bibliografía existente hasta la fecha sobre el efecto que producen diferentes tipos de estrés en la posterior conducta maternal en hembras de ratón, seleccionando principalmente por su importancia dos tipos de conductas: la motivación maternal y la agresión maternal (es decir, tanto conductas dirigidas como no dirigidas a las crías). Para ello, primero describiremos las diferentes metodologías utilizadas para estudiar ambos tipos de conductas y, después, mostraremos los principales estudios que muestran el efecto de diferentes tipos de estrés en dicha conducta. Los resultados observados indican que el estrés modifica la conducta maternal ya que se han observado cambios en motivación y agresión. Sin embargo, algunos datos son ambiguos y varían en función del tipo de estrés o período gestacional/postparto en el que se sufre. A pesar de que más estudios son necesarios en este campo, este trabajo contribuirá al avance del concomiendo en patologías asociadas al estrés y la maternidad.

Palabras clave: comportamiento maternal, estrés, motivación maternal, agresión maternal, hembras de ratón, cerebro socio-sexual. 


\begin{abstract}
Maternal behaviour ensures offspring's survival, until the progeny arrives to sexual maturity. This behavior is regulated by the socio-sexual brain and different factors (such as stress) can alter the neural cores that control its performance. The objective of the present study is to revise the existing bibliography till the date about the effect that different types of stress produce in the future maternal behavior on female mice, selecting by the relevance two types of behaviour: maternal motivation and maternal aggression (behavior directed and non-directed towards pups). First, we will describe the different methodologies used to study both kind of behavior, then we will present the principal studies that shows the effect of different types of stress on behavior. The observed results suggest that stress modifies maternal behavior, because stress changes maternal motivation and maternal aggression. However, some data are ambiguous and vary according to the type of stress or gestational/postpartum period. Although more studies are needed in this field, this work will contribute to the advancement of knowledge in pathologies associated with stress and motherhood.
\end{abstract}

Keywords: maternal behavior, stress, maternal motivation, maternal aggression, female mice, socio-sexual brain.

\title{
Introducción
}

La conducta parental se define como el conjunto de comportamientos llevados a cabo por los progenitores de una especie con el fin de satisfacer las necesidades de la progenie y asegurar la supervivencia de esta hasta que alcanza la madurez sexual, ya que las crías de ciertos animales, en sus primeros momentos de vida, son consideradas inmaduras e incapaces de valerse por sí mismas (Numan e Insel 2003).

Para estudiar la conducta parental, se ha utilizado principalmente el modelo animal de ratón. En esta especie es la madre la que realiza las conductas de cuidado hacia las crías, por lo que hablamos de conducta maternal. La investigación en este campo es idónea en roedores gracias a las siguientes características: su pequeño tamaño, su facilidad para la manipulación, el bajo coste de su mantenimiento, su corto periodo gestacional y su alto número de crías por parto. Pero la característica más representativa que convierte al roedor en un modelo equiparable a la conducta maternal humana es la conservación a lo largo de la evolución de su cerebro socio-sexual (encargado de regular las conductas sociales, entre ellas la conducta maternal), siendo muy similar en todos los mamíferos y que incluye estructuras cerebrales muy profundas y primitivas (tales como estructuras telencefálicas, hipotalámicas y mesencefálicas) que dirigen conductas instintivas (Newman 1999).

Así, el cerebro socio-sexual está formado por un grupo de centros nerviosos interconectados entre sí que se activan de manera diferente de acuerdo con diferentes variables, dando como resultado diferentes patrones de actividad, que a su vez se traducen en diferentes conductas (Newman 1999; Numan e Insel 2003). Diferentes factores como inputs sensoriales, influencia hormonal, experiencia previa y otros factores ambientales (entre los que se encuentra el estrés) pueden afectar al núcleo neuronal que rige la conducta maternal y modificar su patrón, ya 
que cabe destacar que el comportamiento maternal en ratones incluye dos principales tipos de respuestas: a) conductas dirigidas a crías (aseo, abrigo, alimentación, etc.) y $b$ ) conductas no dirigidas a crías (construcción del nido, protección de las crías mediante la agresión maternal, etc.) (Gammie 2005).

Entre estos factores, la influencia del estrés en la conducta maternal es un campo de estudio reciente. El estrés se define como una respuesta no específica del organismo ante cualquier demanda que se le imponga (Selye 1973). Se ha demostrado en trabajos científicos que diferentes tipos de estrés modifican comportamientos en las crías que lo sufren induciendo diferentes problemas (Champagne y Meaney 2006; Tractenberg et al. 2016; Klampfl et al. 2018; Bailoo, Jordan, Garza y Tyler 2014). Sin embargo, el efecto que producen diferentes tipos de estrés (sobre todo algunos como la separación materno-filial) en la madre y su posterior conducta maternal es todavía un campo desconocido.

Por otra parte, es sabido que la motivación es un proceso interno que modifica la manera en que un organismo responde a estímulos externos y que la maternidad incluye un incremento de la motivación por las crías y su cuidado (como conducta dirigida a las crías) (Numan y Woodside 2010). Además, sabemos que la agresión maternal (dentro de las conductas no dirigidas a las crías) permite la defensa de estas de potenciales amenazas (Gammie 2005). Las hembras se sienten atraídas por las feromonas de macho; en cambio, la maternidad provoca cambios en la agresión maternal (Martín-Sánchez et al. 2015a, 2015b) y agreden a los machos de su especie. Este cambio conductual se produce exclusivamente por modificaciones en el cerebro maternal, ya que estudios previos han demostrado que hembras vírgenes (sin contacto con crías) y comadres (hembras vírgenes que acompañan a las madres desde la gestación y después del parto pero no atraviesan periodos de gestación o lactancia) no muestran agresión maternal (Martín-Sánchez et al. 2015b).

Por lo tanto, el objetivo del presente trabajo es revisar y analizar la información existente hasta la fecha sobre el efecto que produce el estrés en la posterior conducta maternal, haciendo énfasis en el análisis de este efecto en la motivación maternal y la agresión maternal, revisando, a su vez, los principales paradigmas que se utilizan para la evaluación de estos dos tipos de conductas maternales.

\section{Método}

\section{Test comportamentales para evaluar motivación maternal}

La motivación maternal se evalúa normalmente por la rapidez y la cantidad de crías que son capaces de recoger y devolver al nido cuando estas están fuera. El test estándar para la evaluación de la motivación maternal es conocido como Pup Retrieval Test (PRT) (Fride, Dan, Gavish y Weinstock 1985) consistente en esparcir a las crías fuera del nido y registrar latencia y número de crías que la madre devuelve al nido. Sin embargo, diferentes modificaciones del test se han llevado a cabo por diferentes autores y diferentes fines experimentales.

Por ejemplo, Klampfl et al. (2018) utilizaron una modificación del PRT en donde se introduce una casa roja (estímulo externo desconocido) en su propia jaula (véase la figura 1). Esta casa es proporcionada a las madres con el fin de ofrecerles un lugar potencial para hacer el nido. El test se lleva a cabo en el día de lactancia 3 y se registran los siguientes comportamientos: el número de crías recogidas en la casa roja y la latencia de recogida de la primera y la última cría. 
A PRT convencional

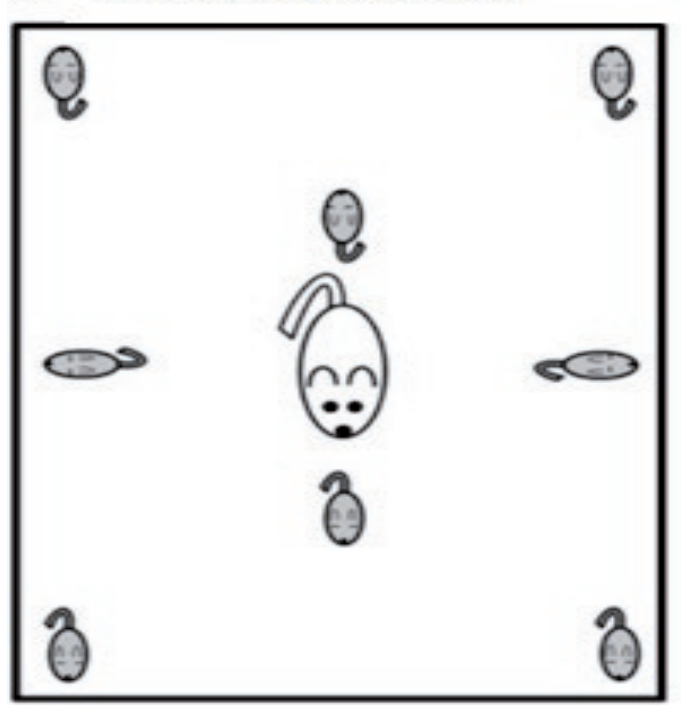

B PRT Modificado

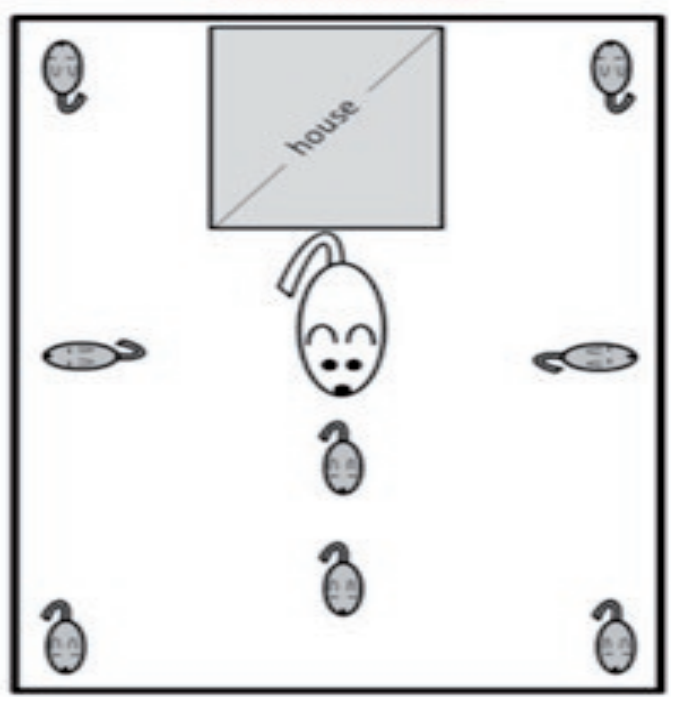

Figura 1: Pup Retrieval Test convencional (A) y modificado (B)

Otra modificación del test fue llevada a cabo por Salais (2017) utilizando el test Pup Retrieval motivado (véase la figura 2). En este caso, las madres tienen que escalar una barrera de malla de alambre de $10 \mathrm{~cm}$ de altura, con el fin de recoger crías que se encuentran detrás, cogerlas en la boca y, con ellas, volver a escalar la valla para llevarlas al nido. Es decir, se trata de un paradigma que evalúa un plus de motivación, ya que la madre ha de hacer un mayor esfuerzo para llevar a las crías al nido que en un simple test Pup Retrieval estándar.

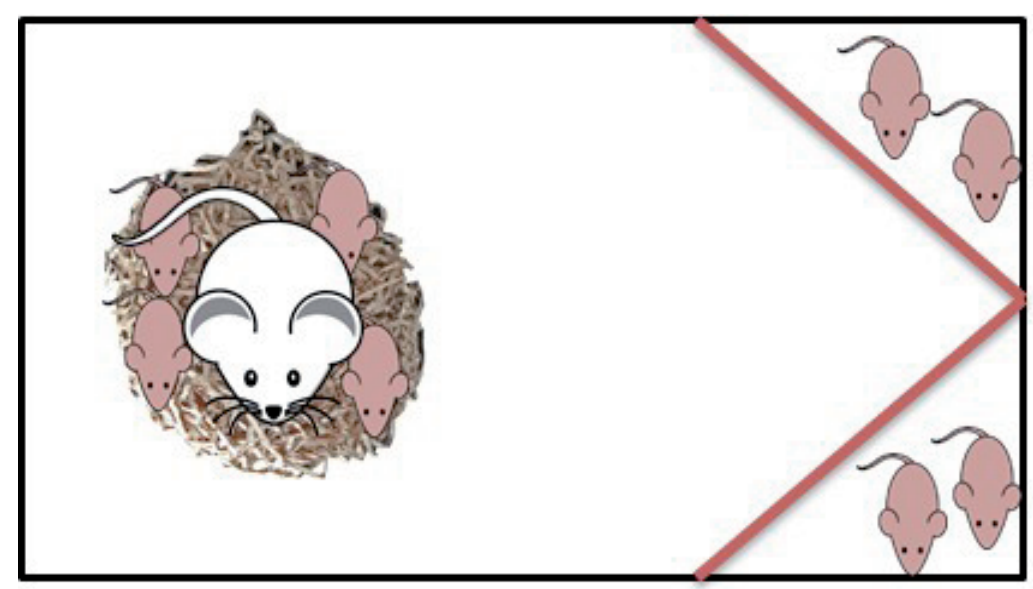

Figura 2: Test Pup Retrieval motivado

Por norma general, los comportamientos registrados son: latencia del primer contacto con crías, el tiempo total de contacto con las crías, latencia de recogida de cada una de las 4 crías colocadas detrás de las barreras y número de veces que la madre atraviesa la barrera. 
Este test puede ser llevado a cabo tanto en madres, comadres o hembras vírgenes para observar la diferente motivación entre diferentes tipos de hembras y estudiar los cambios que se llevan a cabo en motivación tras los cambios cerebrales debidos a la maternidad (Salais 2017).

\section{Test comportamentales para evaluar agresión maternal}

Típicamente, la agresión maternal se evalúa utilizando un test de defensa maternal cuando la madre se encuentra en el día de lactancia 4 o 5 (Neumann, Toschi, Ohl, Torner y Krömer 2001; Martín-Sánchez et al. 2015b) introduciendo a un intruso en la caja hogar de la hembra madre.

Nuevamente, existen diferentes variaciones del test. Por ejemplo, Klampfl, Neumann y Bosch (2013) utilizan como intrusos otras hembras, introduciendo una hembra virgen o una hembra lactante en la caja hogar de la madre en presencia de las crías durante 10 minutos $y$, al finalizar los 10 minutos, se retira la hembra intrusa de la caja (véase la figura 3). Durante el test se registran los comportamientos ofensivos (ataques, amenazas, olfateo de genitales...) y los comportamientos defensivos (erizamiento e inmovilidad).
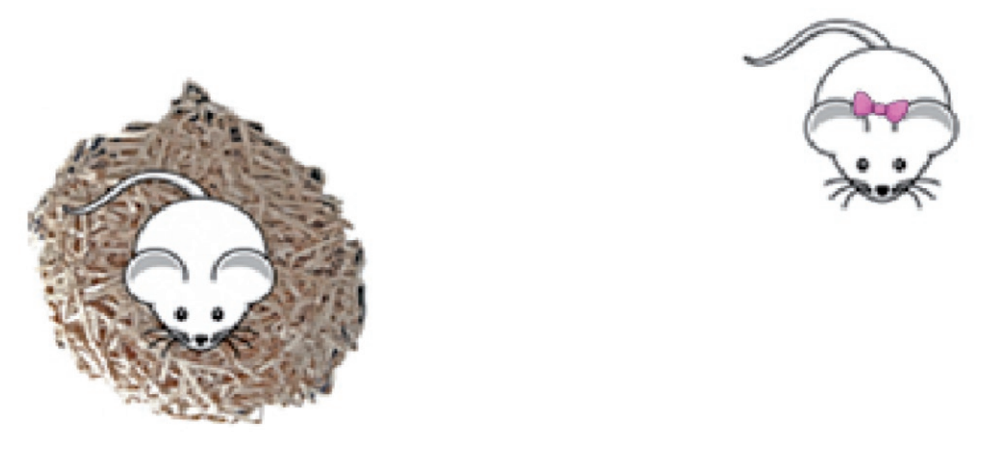

Figura 3: Test de agresión maternal con hembra

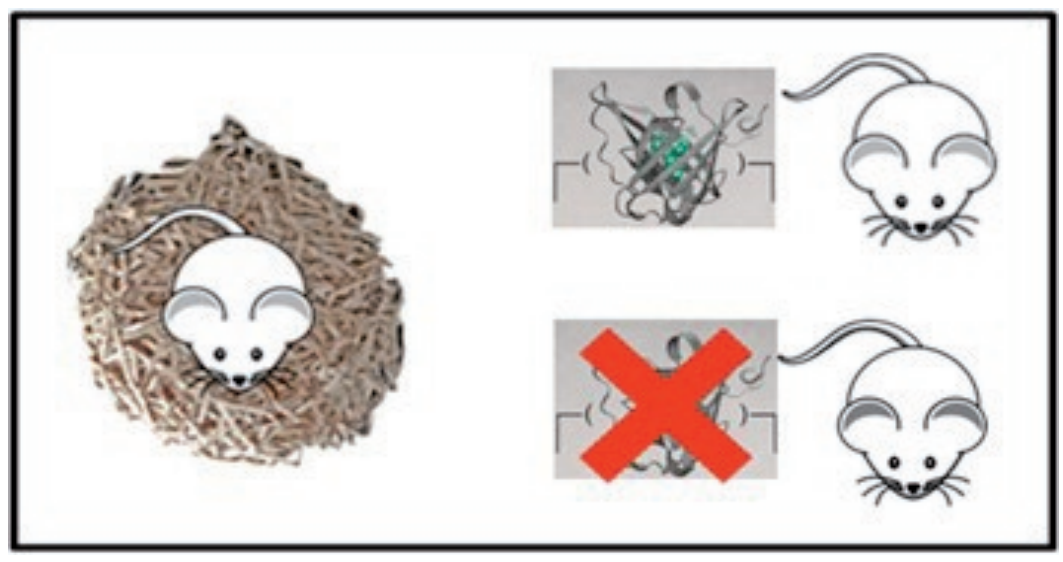

Figura 4: Test de agresión maternal con machos castrados, y rociados con Darcina. 
Otros investigadores, para llevar a cabo este test, utilizan como intrusos a machos (véase la figura 4). En este caso, las crías son retiradas de las cajas para evitar que los machos lleven a cabo la conducta de infanticidio o sean dañadas por los ataques. Para el test de agresión se introduce un macho adulto en la caja de la hembra durante 5 minutos, registrando los ataques o las amenazadas al intruso. Se considera un ataque cuando la hembra, de manera espontánea y activa, muerde o golpea al macho. Además, este test se ha llevado a cabo con machos castrados (que no expresan la feromona Darcina) y con machos castrados pero rociados con la feromona, observando mayor agresión maternal en el segundo caso (Martín-Sánchez et al. 2015a, 2015b).

Este test puede llevarse a cabo con madres, comadres y hembras vírgenes para observar cambios entre los diferentes tipos de hembras en cuanto a la agresión maternal.

\section{Resultados}

Principales resultados obtenidos sobre efectos del estrés en el comportamiento maternal: motivación maternal y agresión maternal

\section{Estrés físico}

Se ha observado que diferentes estímulos estresantes, como el calor, la luz brillante y la música a alto volumen, aumentan la latencia de recogida para la primera cría en el test de Pup Retrieval estándar en madres que no fueron estresadas pero que tienen crías que sí han sido estresadas. Además, el estrés aumenta la agresión maternal de las madres estresadas con crías estresadas y con crías no estresadas ya que las madres estresadas atacan más veces a los machos intrusos que las madres no estresadas (véase la figura 5) (Meek, Dittel, Sheehan, Chan y Kjolhaug 2001).

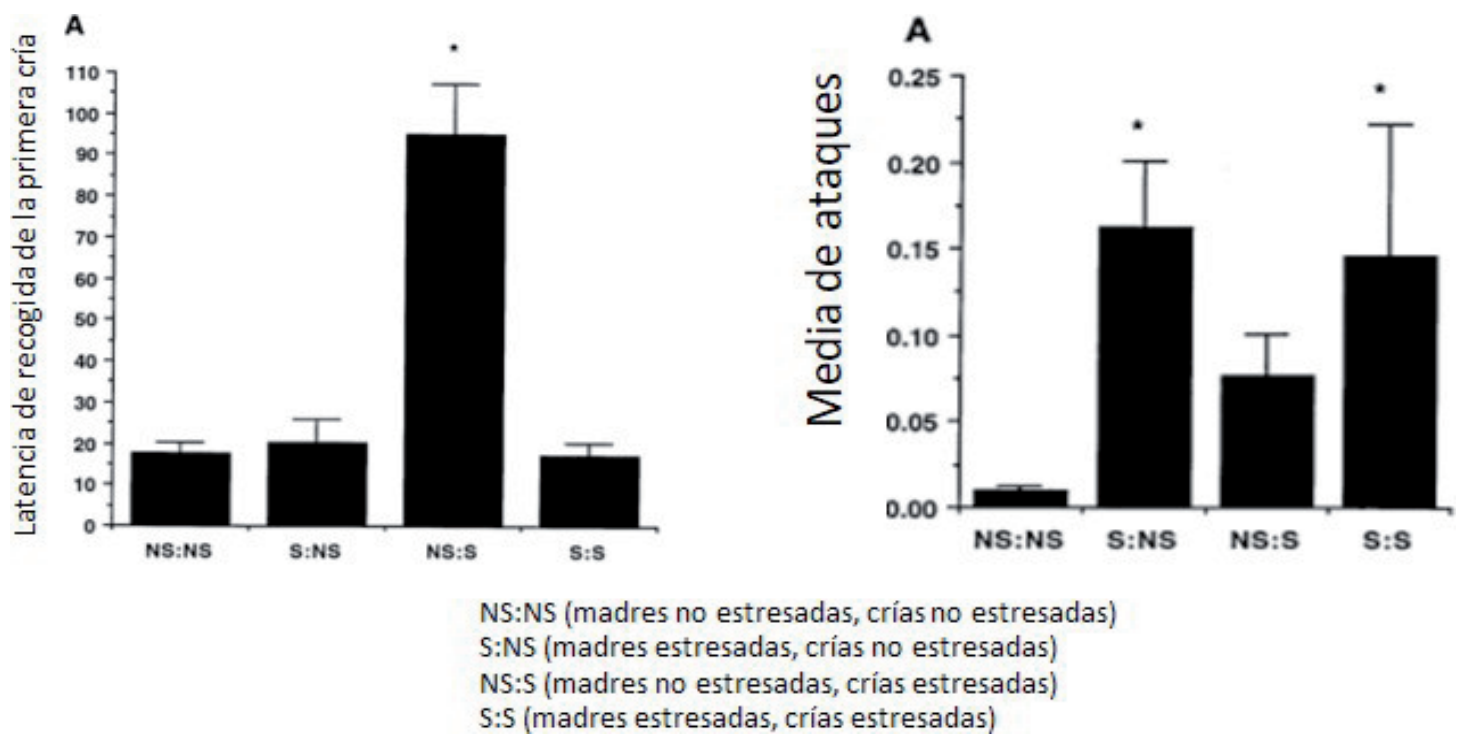

Figura 5: Latencia de recogida para la primera cría y media de ataques 

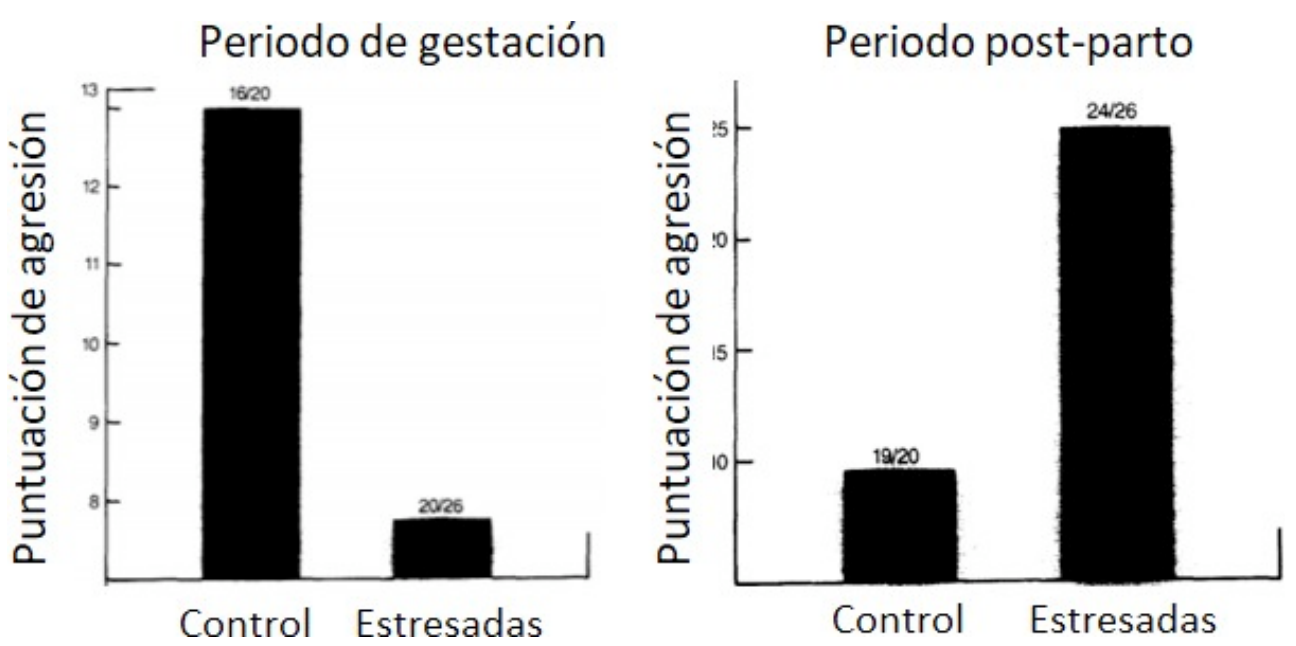

Figura 6: Agresión maternal en hembras gestantes y hembras lactantes, estresadas y no estresadas

Por otra parte, el estrés por calor y restricción (que consiste en poner al roedor en un tubo de plástico que lo mantiene inmóvil con unas bombillas directamente hacia el tubo para dar calor) reduce la agresión maternal en hembras gestantes pero aumenta la agresión en hembras lactantes, comparado con grupos controles (véase la figura 6) (Kinsley y Svare 1988).

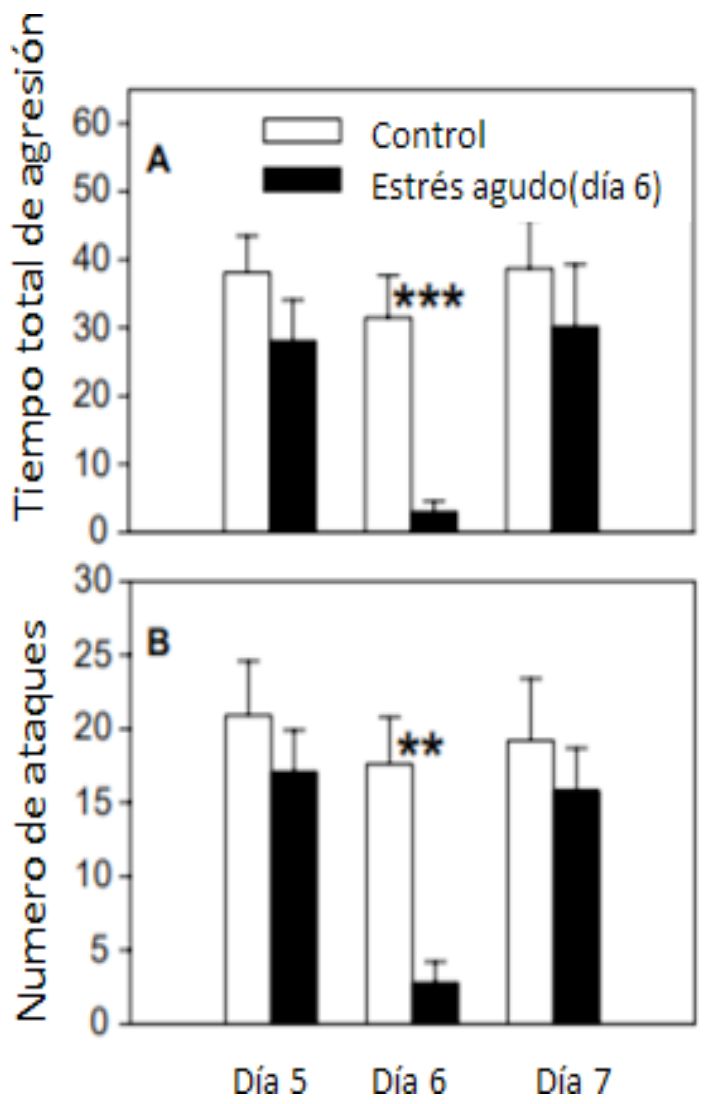

Figura 7: Tiempo total de ataque y número de ataques de hembras estresadas y controles 
También se ha demostrado que el estrés por inmovilización agudo (que consiste en poner al ratón en un tubo de plástico, en el que no puede moverse) disminuye la agresión maternal, ya que las madres estresadas atacan menos tiempo y menos número de veces a los machos intrusos (véase la figura 7) (Gammie y Stevenson 2006).

\section{Estrés social/emocional}

Pocos estudios han demostrado el efecto de la separación materno-filial en el patrón de conducta maternal. Entre los pocos estudios hasta la fecha, se ha demostrado que, al comparar madres separadas de sus crías (como fuente de estrés) con madres no separadas, no se encontraron diferencias en la motivación, pero el patrón de comportamiento maternal era diferente (véase la figura 8). Las madres no separadas en los primeros días mostraban un comportamiento maternal alto, pero este iba disminuyendo; en cambio, las madres separadas primero mostraban un comportamiento maternal bajo que aumentaba con el paso de los días. Esta evaluación del comportamiento maternal se llevó a cabo durante 6 días con un total de 18 observaciones (Orso et al. 2018).

\section{Comportamiento maternal}

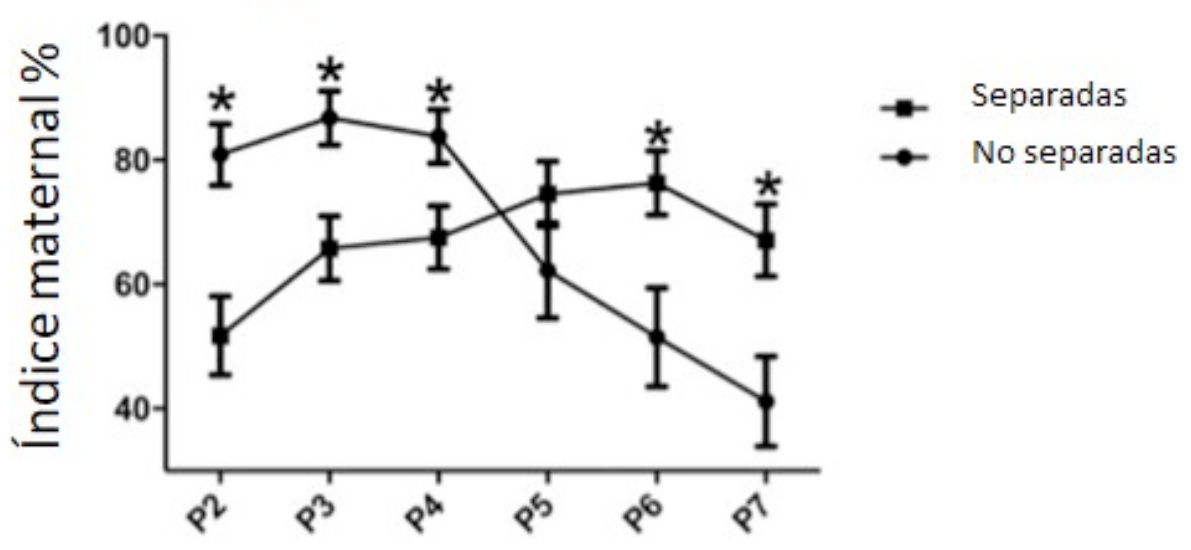

Figura 8: Porcentaje de comportamiento maternal durante 6 días postparto (del día 2 al 7 )

\section{Discusión}

La influencia del estrés en la conducta maternal es un campo que precisa mayor investigación, pues mucho es sabido sobre el efecto que provoca el estrés en las primeras etapas de la vida de las crías y en su posterior desarrollo adulto, pero mucha menos investigación existe hasta la fecha sobre el efecto que el estrés produce en el circuito neural que induce la conducta maternal.

Algunos estudios demuestran que el estrés puede alterar el comportamiento maternal, alterando la oxitocina unida al receptor en núcleos como: bed nucleos terminalis (BNST), área preóptica medial (MPOA), septum lateral (LS), núcleo central de la amígdala (cAMYG) y el hipotálamo ventral medial (VMH). Además, se ha evidenciado que dichas alteraciones son transmitidas a futuras generaciones, ya que la camada que no sufrió el estrés, pero sus madres sí, mostraron las 
mismas alteraciones (Champagne y Meaney 2006). Sin embargo, en relación al efecto que produce el estrés en la conducta maternal motivada (como comportamiento dirigido a las crías) y la agresión maternal (como comportamiento no dirigido a las crías), los estudios son muchos más escasos.

En relación al efecto que produce el estrés en la motivación maternal, encontramos que las madres no estresadas pero que tienen crías que sí han sido estresadas tardan más tiempo en recoger la primera cría (Meek, Dittel, Sheehan, Chan y Kjolhaug 2001), aunque no existen diferencias por sí mismas entre madres estresadas y no estresadas. Esto nos puede indicar que la motivación maternal no se ve afectada por el estrés físico, pero puede verse afectada por el estado en el que se encuentran las crías.

En cuanto a la relación entre estrés físico y la agresión maternal, hemos encontrado que, durante la gestación, las hembras a las que se les induce estrés mediante el calor y la restricción presentan menos agresión maternal que las controles. Por el contrario, si el estrés se induce en el periodo postparto, las hembras estresadas presentan más agresión maternal que las no estresadas (Kinsley y Svare 1988), infiriendo que los cambios hormonales derivados de los últimos días de gestación y postparto son determinantes para la inducción de tal agresión y la mediación de la respuesta al estrés.

En otros estudios en donde se induce estrés mediante calor, luz y música de alto volumen, las madres estresadas atacan un mayor número de veces a los machos intrusos, en comparación con las madres no estresadas (Meek, Dittel, Sheehan, Chan y Kjolhaug 2001). Por el contrario, el estrés agudo inducido por inmovilización disminuyó la agresión maternal: las madres estresadas atacan menos tiempo y en menor medida a los machos (Gammie y Stevenson 2006). Estos resultados nos indican que diferentes tipos de estrés pueden afectar de manera distinta al eje hipotálamo-hipofiso-adrenal y, en consecuencia, a su respuesta a la conducta maternal posterior.

Por último, y siendo el dato más novedoso y relevante para nuestro estudio, se ha observado que la separación materno-filial provoca cambios en el patrón comportamental de las madres, ya que las madres que han sido separadas de sus crías muestran un patrón de cuidado mucho más ansioso, siendo sobreprotectoras a lo largo del tiempo, algo que no se observa en madres no separadas (Orso et al. 2018). En ratas, se ha demostrado que la maternidad provoca cambios en la expresión de CRF cerebral provocando que las madres presenten una mejor respuesta al estrés, bajada de ansiedad y control del miedo (Stern, Goldman y Levine 1973; Bitran, Hilvers y Kellogg 1991), tratándose de una respuesta totalmente adaptativa para llevar a cabo la crianza. En ratones, sin embargo, es posible que, al inducir una separación materno-filial de 3 horas, la expresión de CRF se vea modifica y esto provoque un cambio en la respuesta a estímulos estresantes y, en consecuencia, cambios en el estilo maternal, volviéndose este mucho más sobreprotector a lo largo del tiempo, que es precisamente lo que observamos en este estudio (Orso et al. 2018).

En conclusión, diferentes tipos de estrés son capaces de modificar la posterior conducta maternal. Parece evidente que las madres estresadas (mediante estímulos físicos) muestran más agresión hacía los intrusos. Sin embargo, los datos en relación a la motivación maternal son menos evidentes y más investigación es necesaria para poder llegar a conclusiones. Por otra parte, la gran mayoría de estudios existentes hasta la fecha en este ámbito muestran el efecto de estresores físicos, pero el efecto de otros tipos de estresores en la madre, 
como la separación materno-filial, han sido muy poco estudiados y futuras líneas de investigación bajo esta perspectiva son necesarias. En cualquier caso, el presente trabajo contribuirá al avance del conocimiento en los circuitos neurales que pueden verse afectados por el estrés, su influencia en la posterior conducta maternal y sus patologías asociadas, tales como ansiedad y depresión postparto.

\section{Referencias bibliográficas}

Bailoo, Jeremy D., Richard L. Jordan, Xavier J. Garza y Amber N. Tyler. 2014. «Brief and long periods of maternal separation affect maternal behavior and offspring behavioral development in C57BL/6 mice». Developmental Psychobiology 56(4): 674-685.

Bitran, Daniel, Robert J. Hilvers y Cheryl K. Kellogg. 1991. "Ovarian Endocrine Status Modulates the Anxiolytic Potency of Diazepam and the Efficacy of $\mathrm{Y}$ Aminobutyric Acid-Benzodiazepine Receptor-Mediated Chloride Ion Transport». Behavioral Neuroscience 105(5), 653-662.

Champagne, Frances A. y Michael J. Meaney. 2006. «Stress during gestation alters postpartum maternal care and the development of the offspring in a rodent model». Biological psychiatry 59(12): 1227-1235.

Fride, Ester, Yael Dan, Moshe Gavish y Marta Weinstock. 1985. «Prenatal stress impairs maternal behavior in a conflict situation and reduces hippocampal benzodiazepine receptors». Life Sciences 36(22): 2103-2109.

Gammie, Stephen C. 2005. "Current models and future directions for understanding the neural circuitries of maternal behaviors in rodents». Behavioral and Cognitive Neuroscience Reviews 4: 119-135.

Gammie, Stephen C. y Sharon A. Stevenson. 2006. «Effects of daily and acute restraint stress during lactation on maternal aggression and behavior in mice». Stress 9(3): 171-180.

Kinsley, Craig Howard y Bruce Svare. 1988. «Prenatal stress alters maternal aggression in mice». Physiology and Behavior 42(1): 7-13.

Klampfl, Stefanie M., Inga D. Neumann y Oliver J. Bosch. 2013. «Reduced brain corticotropin- releasing factor receptor activation is required for adequate maternal care and maternal aggression in lactating rats». European Journal of Neuroscience 38(5): 2742-2750.

Klampfl, Stefanie M., Milena M. Schramm, Barbara M. Gaßner, Katharina Hübner, Audrey F. Seasholtz, Paula J. Brunton, Doris S. Bayerl y Oliver J. Bosch. 2018. "Maternal stress and the MPOA: Activation of CRF receptor 1 impairs maternal behavior and triggers local oxytocin release in lactating rats». Neuropharmacology 133: 440-450.

Martín-Sánchez, Ana, Lynn McLean, Robert J. Beynon, Jane L. Hurst, Guillermo Ayala, Enrique Lanuza y Fernando Martínez-Garcia. 2015a. «From sexual attraction to maternal aggression: When pheromones change their behavioural significance». Hormones and Behavior 68: 65-76.

Martín-Sánchez, Ana, Guillermo Valera-Marín, Adoración Hernández-Martínez, Enrique Lanuza, Fernando Martínez-García y Carmen Agustín-Pavón. 2015b. «Wired for motherhood: induction of maternal care but not maternal aggression in virgin female CD1 mice». Frontiers in Behavioral Neuroscience 9(July): 1-12.

Meek, Leslie R., Patricia L. Dittel, Maureen C. Sheehan, Jing Y. Chan y Sarah R. Kjolhaug. 2001. «Effects of stress during pregnancy on maternal behavior in mice». Physiology \& Behavior72(4): 473-479.

Neumann, Inga D., Nicola Toschi, Frauke Ohl, Luz Torner y Simone A. Krömer. 2001. "Maternal defence as an emotional stressor in female rats: Correlation of neuroendocrine and behavioural parameters and involvement of brain oxytocin». European Journal of Neuroscience 13(5): 1016-1024. 
Newman, Sarah Winans 1999. "The medial extended amygdala in male reproductive behavior. A node in the mammalian social behavior network». Annals of the New York Academy of Sciences 877: 242-257.

Numan, Michael y Barbara Woodside. 2010. «Maternity: Neural Mechanisms, Motivational Processes, and Physiological Adaptations». Behavioral Neuroscience 124(6): 715-741.

Numan, Michael y Thomas R. Insel. 2003. The neurobiology of parental behavior. New York: Springer.

Orso, Rodrigo, Luis Eduardo Wearick-Silva, Kerstin Camile Creutzberg, Anderson Centeno-Silva, Laura Glusman Roithmann, Rafaelly Pazzin, Saulo Gantes Tractenberg, Fernando Benetti y Rodrigo Grassi-Oliveira. 2018. «Maternal behavior of the mouse dam toward pups: implications for maternal separation model of early life stress». Stress 21(1): 19-27.

Salais, Hugo 2017. Mapping the actions of prolactin in the mouse brain. Sexual Dimorphism, Steroid Regulation and the Neuroendocrinology of Maternal Behaviour. Tesis doctoral. Castellón: Universitat Jaume I.

Selye, Hans. 1973. "The Evolution of the Stress Concept: The originator of the concept traces its development from the discovery in 1936 of the alarm reaction to modern therapeutic applications of syntoxic and catatoxic hormones». American Scientist 61(6): 692-699.

Stern, Judith M., Larry Goldman y Seymour Levine. 1973. «Pituitaryadrenal responsiveness during lactation in rats». Neuroendocrinology 12(3): 179191.

Tractenberg, Saulo Gantes, Mateus L. Levandowski, Lucas A. de Azeredo, Rodrigo Orso, Laura G. Roithmann, Emerson S. Hoffmann, Heather C. Brenhouse y Rodrigo Grassi-Oliveira. 2016. "An overview of maternal separation effects on behavioural outcomes in mice: Evidence from a fourstage methodological systematic review». Neuroscience and Biobehavioral Reviews 68: 489-503. 